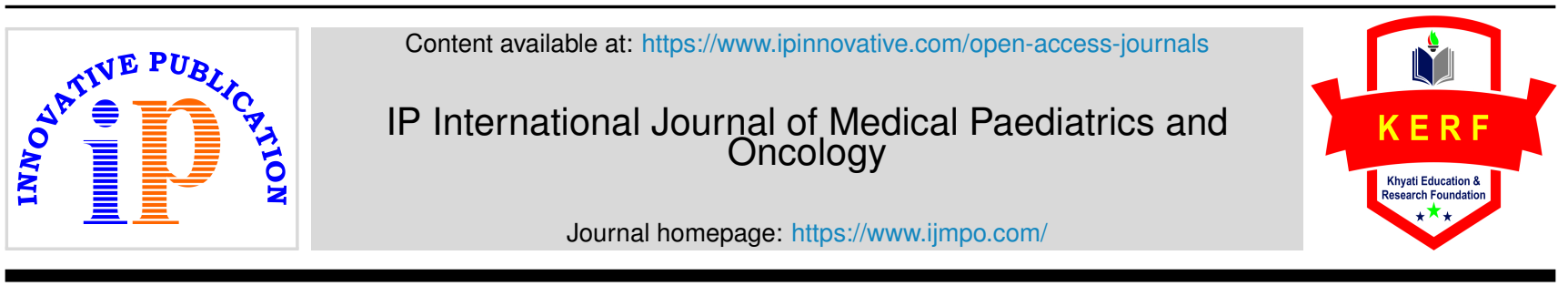

Original Research Article

\title{
Outcome of management of preterm babies born below 34 weeks of gestation in a level - 3 Neonatal ICU of a teaching institution in a backward district of Kerala- A retrospective analysis
}

\author{
Venugopalan', Manoj Narayanan K A ${ }^{1}$ 1,* \\ ${ }^{1}$ Dept. of Pediatrics, DM WIMS Medical College Hospital, Wayanad, Kerala, India
}

\section{A R T I C L E I N F O}

\section{Article history:}

Received 29-01-2021

Accepted 24-02-2021

Available online 25-03-2021

\section{Keywords:}

Preterm

Gestational Age

Low Birth Weight

Surfactant

Congenital Anomalies

\begin{abstract}
A B S T R A C T
Background: Preterm birth is considered as the main cause of neonatal morbidity and mortality. This also results in major sequelae in surviving children. It is essential to establish the factors leading to preterm delivery and the clinical profile of preterm infants. This is particularly important in a backward district where $20 \%$ of populations are tribal with poor access to health care. This study retrospectively analyses the outcome of care of preterm infants in a level 3 NICU.

Objectives: I) To study the outcome of management of preterm babies below 34 weeks of gestational age at birth in a backward district of Kerala. 2) To evaluate the risk factors for mortality and permanent sequelae in these babies.

Materials and Methods: This is a retrospective analysis of hospital records of preterm infants admitted in a neonatal ICU of a tertiary teaching hospital for one year from $1^{s t}$ of January 2017 till $31^{s t}$ of December 2017. Both inborn and out born infants born below 34 weeks of gestational age are included. Maternal and baby related factors are taken into account. All the infants are provided level 3 care and the details of the treatment and outcome are studied. The data are entered in Microsoft excel and analyzed.

Results: Out of the 1036 babies admitted in this NICU over the year (01/01/2017 to 31/12/2017) 141 preterm babies who were born below 34 weeks of gestational age are included in this study. Lowest gestational age was 24 weeks. Lowest birth weight recorded is 364 grams. 6 infants died in the hospital and birth weight and gestational age are directly related to mortality.

Conclusion: Out of 141 preterm infants, with a gestational age below 34 weeks' gestational age at birth, admitted in the NICU, $6(4.25 \%)$ died. Majority died in the first week of admission. Most of the children had multiple congenital anomalies and comorbid illnesses which is managed successfully in the NICU. Shortest hospital stay was 1 day and longest stay was 79 days, with a mean of 21 days.
\end{abstract}

(c) This is an open access article distributed under the terms of the Creative Commons Attribution License (https://creativecommons.org/licenses/by/4.0/) which permits unrestricted use, distribution, and reproduction in any medium, provided the original author and source are credited.

\section{Introduction}

Preterm birth is a major cause of neonatal morbidity and mortality worldwide. It is also the main contributory factor for mental and physical retardation acquired after birth. Except for congenital malformations, $75 \%$ of perinatal deaths and $50 \%$ of neurological abnormalities are directly attributed to preterm birth. ${ }^{1-3}$ Due to advances in technology and improvements in neonatal care, several

\footnotetext{
* Corresponding author.

E-mail address: manojnryn@gmail.com (M. Narayanan K A).
}

preterm newborn babies survive with least sequelae. However, many of them remain vulnerable to long term complications that may persist throughout their lives. Among the main long term morbidities are neurosensory deficits (blindness, deafness), necrotizing enterocolitis, intraventricular hemorrhage, broncho-pulmonary dysplasia and delay in physical and mental development. ${ }^{4,5}$ This study focuses on the outcome of preterm babies born below 34 weeks of gestational age treated in a level-3 NICU of a tertiary care teaching hospital in Wayanad, a backward district of Kerala. This study is done in the NICU of 
Doctor Mooppen's Wayanad Institute of Medical Sciences (DMWIMS) Medical College Hospital, the only medical teaching institution in the district and the only hospital with level 3 NICU. This facility caters to a total population of about twenty lakhs taking in to account adjacent areas of neighboring districts of the state and the states of Tamilnadu and Karnataka. Tertiary level health care facilities and level 3 NICU care are not available anywhere nearby.

\section{Objectives}

1. To study the outcome of management of preterm babies admitted in a level 3 NICU of a backward district of Kerala.

2. To evaluate the risk factors for mortality and permanent sequelae in these babies.

\section{Materials and Methods}

This is a retrospective analysis of hospital records of preterm infants admitted in a neonatal ICU of a tertiary level teaching hospital for a period of one year from $1^{\text {st }}$ of January 2017 till $31^{\text {st }}$ of December 2017. Both inborn and out born infants born below 34 weeks of gestational age are included. 34 weeks of gestational age at birth is taken as a cutoff age since babies born above 34 weeks of gestational age are neurogically mature for sucking at the breast and taking oral feeds. Maternal factors like Parity, Anemia, Gestational Diabetes Mellitus (GDM), Antepartum Hemorrhage (APH), Pregnancy Induced Hypertension (PIH) and Cesarean Section (CS) are recorded. Fetal factors such as Birth Weight, Weight on Admission to NICU, Length of Hospital Stay (LOS), Infection, Respiratory Distress Syndrome (RDS), Congenital Anomalies and Death during hospital stay are noted. All the infants are treated in a level $3 \mathrm{NICU}$ and the type of treatment and outcome are studied. The data analysis will be carried out by subgroups according to gestational age at birth of these preterm babies, probable causes for preterm birth, birth weight, therapeutic interventions, and outcome at discharge. Then, the respective rates, ratios and relative risks will be estimated for the possible predictors.

\subsection{Definitions}

Moderate preterm: Gestational age from 32 to 36 completed weeks.

Very-preterm: Gestational age between 28 to 31 completed weeks.

Extreme preterm: Gestational age less than 28 completed weeks.

Low birth weight: $<2500 \mathrm{~g}$

Very low birth weight: $<1500 \mathrm{~g}$

Extremely low birth weight: $<1000 \mathrm{~g}$

\section{Results}

A total of 141 infants born below 34 weeks of gestation were included in this retrospective cohort study. Mean birth weight increased with increasing gestational age, from 354 $\mathrm{g}$ at 24 weeks to $2450 \mathrm{~g}$ at 34 weeks. 77 infants in the cohort were males $(54.6 \%)$ and $64(45.4 \%)$ were females (Table 1$)$.

Table 1: Sex distribution among preterm babies

\begin{tabular}{lcc}
\hline Sex & No. & Percentage \\
Male & 77 & 54.6 \\
Female & 64 & 45.4 \\
Total & 141 & \\
\hline
\end{tabular}

122 babies were born in this hospital and 19 were born in peripheral hospitals and referred in for neonatal care (Figure 1)

\section{Site of Birth}

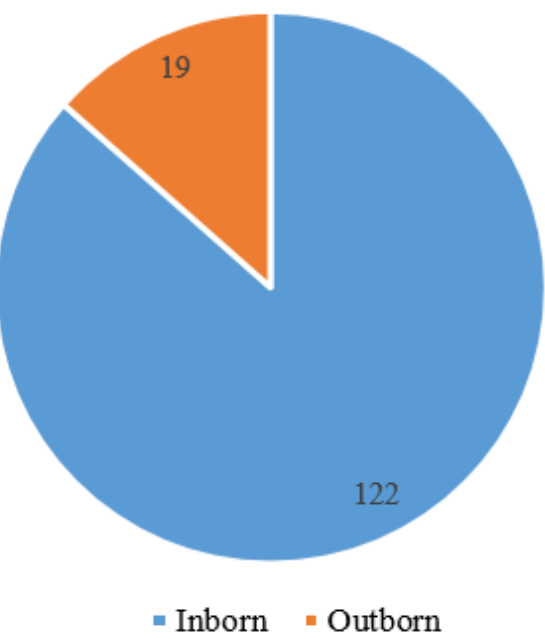

Fig. 1: Number of inborn andoutborn babies

Among these $15(10.6 \%)$ were between 24 to 28 weeks of gestation, $21(14.9 \%)$ were between 29 to 31 weeks of gestation and $105(74.5 \%)$ were between 32 to 34 weeks of gestation (Figure 2). Out of these 20 (14.2\%) were born of cesarean section, $8(5.6 \%)$ babies were of extremely low birth weight, 32 (22.7\%) were between 1000-1500 gm and $101(71.7 \%)$ were between 1500 to $2500 \mathrm{gm}$ weight category (Figure 3). There were 6 deaths $(4.25 \%)$ out of which only one was among the extremely low birth weight category (Figure 4).

Minimum stay in the hospital was I day and maximum was 79 days with a mean of 21 days. Out of 6 deaths 5 occurred in the first week and one in the third week. Major anomalies detected were Down Syndrome with Congenital Heart Diseases, ASD, PDA, Hydrocephalus, Retinopathy of Prematurity (ROP), Limb and Chest Wall abnormalities, Jejunal Atresia, Undescended Testes, 


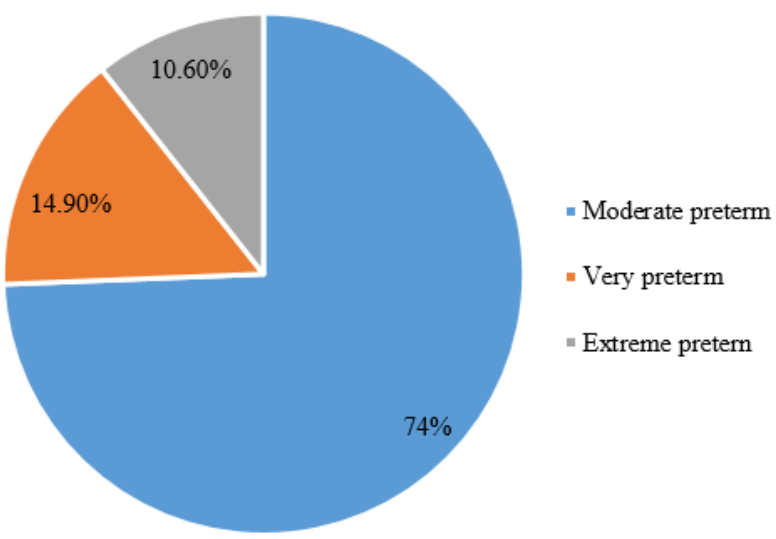

Fig. 2: Number of infants born at different gestational ages
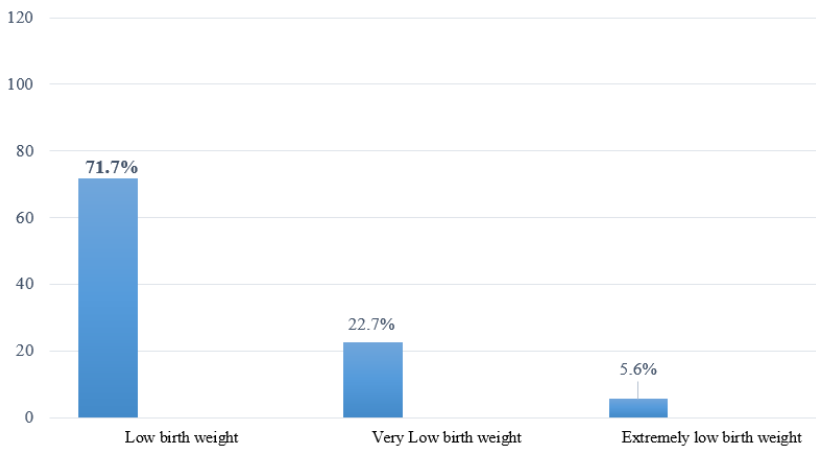

Fig. 3: Number of children in different weight groups

\section{Outcome}

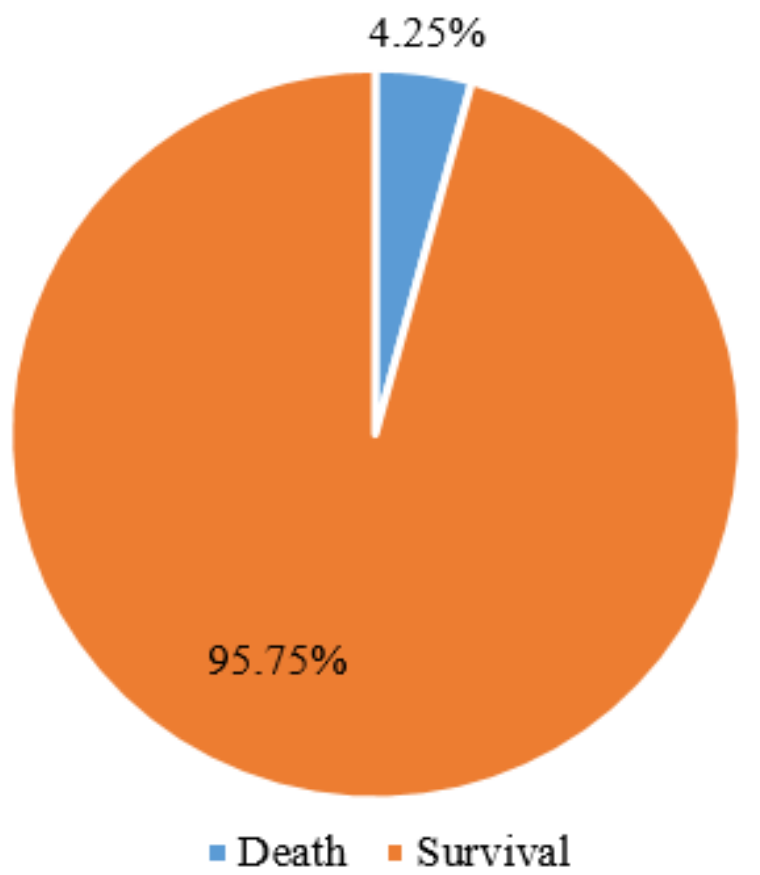

Fig. 4: Death among preterm infants
Tracheoesophageal Fistula and Hydro-uretero-nephrosis (Table 2). Multiple major abnormalities were detected more in infants born below 31 weeks of gestation. Major associated comorbidities noted were Perinatal Asphyxia, Hyaline Membrane Disease(HMD), Respiratory Distress, Neonatal Sepsis, Hypoglycemia, Neonatal Hyperbilirubinaemia, Pneumothorax, Metabolic Acidosis and Multi Organ Dysfunction Syndrome (MODS) (Table 3).

Respiratory distress was present in $34(24.1 \%)$ infants, ASD in $4(2.8 \%)$ and Retinopathy of prematurity (ROP) in $6(4.25 \%)$ infants.

Table 2: Major congenital anomalies detected during hospital stay

\begin{tabular}{llcc}
\hline S.No. & $\begin{array}{l}\text { Congenital } \\
\text { anomalies detected } \\
\text { Down syndrome } \\
\text { with congenital } \\
\text { heart disease }\end{array}$ & Number & Percentage \\
& ASD & $0.7 \%$ \\
2 & PDA & 3 & $2.1 \%$ \\
3 & Hydrocephalus & 2 & $2.1 \%$ \\
4 & Lung immaturity & & $1.40 / 0$ \\
5 & Retinopathy of & $0.7 \%$ \\
6 & Prematurity (ROP) & & \\
7 & Limb and chest wall & & $0.7 \%$ \\
8 & abnormalities & & $0.7 \%$ \\
9 & Jejunal Atresia & & $0.7 \%$ \\
10 & Undescended testes & & $0.7 \%$ \\
11 & Tracheo esophageal & & $0.7 \%$ \\
12. & Fistula & & \\
\hline & Hydro-uretero- & & $0.7 \%$ \\
\hline
\end{tabular}

Table 3: Neonatal complications during hospital stay

\begin{tabular}{llcc}
\hline S.No. & $\begin{array}{l}\text { Complications } \\
\text { during hospital } \\
\text { stay }\end{array}$ & Number & Percentage \\
1 & $\begin{array}{l}\text { Perinatal Asphyxia } \\
2\end{array}$ & 9 & $6.4 \%$ \\
& $\begin{array}{l}\text { Hyaline Membrane } \\
\text { Disease }\end{array}$ & & $0.7 \%$ \\
3 & Respiratory & 34 & $24.11 \%$ \\
4 & Distress & 10 & $7.1 \%$ \\
5 & Neonatal Sepsis & 2 & $\mathrm{I} .40 / 0$ \\
6 & Hypoglycemia & 51 & $36.17 \%$ \\
7 & Neonatal Hyper- & & \\
8 & Bilirubinaemia & 2 & $1.4 \%$ \\
9 & Pneumothorax & 1 & $0.7 \%$ \\
& Metabolic Acidosis & 1 & $0.7 \%$ \\
& Multi Organ & & \\
\hline
\end{tabular}

No single maternal cause was attributable to prematurity. Most of the mothers were primi gravidae $(41.1 \%)$ or second gravidae (34.75\%). There were $15(10.6 \%)$ twin pregnancies. Other maternal factors noticed are Pregnancy 
Induced Hypertension (PIH) in 9 mothers, Gestational Diabetes Mellitus in 4, Ante Partum Hemorrhage in 2 and Anemia in 2 mothers respectively. All the preterm deliveries were attended by pediatrician. All preterm deliveries were informed to NICU prior to delivery and most of the cases referred from outside are informed while being referred in, so that arrangement for receiving the baby in the NICU was undertaken. All babies $<34$ weeks of gestational age at birth were invariably shifted to NICU for preterm care. $22(17 \%)$ babies needed resuscitation at birth. All the premature infants were nursed in thermo-neutral environment (around $36.5^{\circ} \mathrm{C}$ ). Oil is applied to skin to reduce convective heat loss and evaporative water loss. Babies once they are stable are given kangaroo 4.25 mother care to provide warmth. All preterm infants developed jaundice within the first week. If baby is found to be jaundiced, serum bilirubin is done and phototherapy started based on bilirubin level. Jaundice was not controlled by phototherapy in one baby and was subjected to exchange transfusion.

Co morbid illnesses and complications were controlled with NICU management and 135 babies were discharged in good condition. 24 babies had congenital anomalies out of which 9 babies with ROP were referred out for further management. Advice as appropriate was given for management of undescended testes, cleft lip, hydro-ureteronephrosis, tracheo-esophageal fistula and jejunal atresia.

\section{Discussion}

Preterm birth is a major cause of neonatal morbidity and mortality worldwide. It is also the main cause responsible for deficiencies acquired after birth. Preterm newborn babies represented $12.5 \%$ of live births in the United States in $2004 .{ }^{6}$ Preterm births are spontaneous in $75 \%$ of the cases. ${ }^{7}$ In this study preterm births are spontaneous in $85.8 \%$ of cases and caesarian section had to be done in $20(14.2 \%)$ cases. It is reported that more than half are associated with preeclampsia, fetal distress, intrauterine growth restriction, abruptio-placentae, and placental insufficiency. ${ }^{8}$ But in our study maternal factors such as PIH, APH, GDM and anemia are not found to be significantly contributing to prematurity. Respiratory distress $(24.11 \%)$, sepsis $(7.1 \%)$ and perinatal asphyxia (6.4\%) are significantly high in this cohort and may be contributed by prematurity. It is reported that approximately half the spontaneous preterm births are associated with intrauterine infection, which triggers the maternal and fetal infections leading to preterm labor. ${ }^{9}$ There are many studies showing the association between infections such as periodontal disease and bacterial vaginoses with preterm labor and premature rupture of membranes. ${ }^{10,11}$ There is strong relationship between multiple pregnancies and preterm birth, and prematurity is the main complication in these pregnancies. ${ }^{12}$ In this study $10.6 \%$ of cases had multiple pregnancies.
Even though sepsis, respiratory distress and ROP have been reported among this cohort it is less when compared to other studies. ${ }^{13}$ Few other studies have shown higher rates of cerebral palsy, cognitive impairment, and behavioral problems among those born at very early gestations. ${ }^{14-17}$ and causing major neonatal morbidities and high risk for significant impairment in later life. The rates of attempted resuscitation for infants in our study were similar to several other studies. ${ }^{18}$ These infants received interventions such as chest compressions, Surfactant therapy, tracheal intubation, ventilator support or parenteral nutrition. It is possible that the differences in resuscitation practices may influence quality of survival and mortality. Previous studies have proposed individual decision-making in resuscitation of extremely preterm infants. ${ }^{19,20}$ whereas other studies have examined more major differences in resuscitation practice and subsequent outcomes at the hospital leve1. ${ }^{21,21}$ Population-based studies and analyses are needed to gain a better understanding of the determinants of and extent to which regional practice variations influence mortality and survival rates.

Death among preterm infants is only $6(4.25 \%)$ in this cohort. Out of 8 extremely low birth weight infants only one died from the hospital. Majority of extremely preterm births in this cohort occurred in hospitals and this may be the reason for low mortality. Out of 141 preterm infants, 135 infants could be discharged from the NICU in good condition. This highlights the comprehensive care given by the team in this level-3 NICU. Increase in survival was seen in infants born at a tertiary teaching hospital with a level-3 NICU, which has been reported in other studies. ${ }^{22,23}$

\section{Conclusion}

Outcome of management of premature babies in this level-3 NICU of a backward district is comparable with other NICUs across the world with a survival of $95.75 \%$. Maternal factors that contribute to preterm births are multiple pregnancies, being primi gravida and perinatal sepsis. Neonatal morbidities contributed by prematurity are perinatal asphyxia, respiratory distress and sepsis. Factors contributing to mortality are multiple congenital anomalies, respiratory distress and septicemia. What is further required is detailed analysis of cause of death other than complex congenital anomalies. This would help in formulating strategies to further improve the outcome in neonatal period. Also a close follow up till 6 months to one year of age should be there to assess the quality of survival, possible sequelae and their standard management.

\section{Conflicts of Interest}

All contributing authors declare no conflicts of interest. 


\section{Source of Funding}

None.

\section{References}

1. Germain AA. Enrique OE: Parto prematuro. Rev Chil Obstet Ginecol. 1996;61:189203.

2. Marlow N, Wolke D, Bracewell MA, Samara M. EPICure Study Group: Neurologic and developmental disability at six years of age after extremely preterm birth. N Engl J Med. 2005;352:9-19.

3. Martin JA, Hamilton BE, Sutton PI, Ventura SJ, Menacker F, Kirmeyer $\mathrm{S}$, et al. Centers for Disease Control and Prevention National Center for Health Statistics National Vital Statistics System: Births: final data for 2005. Natl Vital Stat Rep. 2007;56:86.

4. Cram LF, Zapata ML, Toy EC, Baker B. Genitourinary infections and their association with preterm labor. Am Fam Physician. 2002;65:2418 .

5. Carvalho MI, Bittar RE, Maganha PPA, Pereira SV, Zugaib M. Genitourinary infections and their association with preterm labor. Rev Bras Ginecol Obstet. 2001;23:529-33.

6. Institute of Medicine: Preterm birth: causes, consequences, and prevention. Washington (DC): The National Academies Press; 2007.

7. Martin JA, Hamilton BE, Sutton PI, Ventura SJ, Menacker F, Kirmeyer $\mathrm{S}$, et al. Centers for Disease Control and Prevention: National Center for Health Statistics National Vital Statistics System. Births: final data for 2005. Natl Vital Stat Rep. 2007;56:1-103.

8. Ananth CV, Vintzileos AM. Maternal-fetal conditions necessitating a medical intervention resulting in preterm birth. Am J Obstet Gynecol. 2006;195(6):1557-63. doi:10.1016/j.ajog.2006.05.021.

9. Klein LL, Gibbs RS. View ArticlePubMedGoogle Scholar. Obstet Gynecol Clin North Am. 2005;32(3):397-410. do1:10.1016/..ogc.2005.03.001

10. Polyzos NP, Polyzos IP, Mauri D, Tzioras S, Tsappi M, Cortinovis I, et al. Effect of periodontal disease treatment during pregnancy on preterm birth incidence: a metaanalysis of randomized trials. AM J Obstet Gynecol. 2009;200(3):225-32. do1:10.1016/j.ajog.2008.09.020

11. Mcdonald H, Brocklehurst P, Gordon A. Antibiotics for treating bacterial vaginosis in pregnancy. Cochrane Database Syst Rev. 2005;24(1):CD000262.

12. Bornstein E, Proudfit CL, Keeler SM. Prematurity in twin pregnancies. Minerva Ginecol. 2009;2:113-26.

13. Ancel PY, Goffinet F, Kuhn P. Survival and morbidity of preterm children born at 22 through 34 weeks' gestation in France in 2011 : results of the EPIPAGE-2 cohort study [published correction appears in JAMA Pediatr. JAMA Pediatr. 2015;169(4):230-8.

14. Delobei-Ayoub M, Arnaud C, White-Koning M. EPIPAGE Study Group. Behavioral problems and cognitive performance at 5 years of age after very preterm birth: the EPIPAGE study. Pediatr. 2009;123(6):1485-92.

15. Marlow N, Wolke D, Bracewell MA, Samara M. EPICure Study Group. Neurologic and developmental disability at six years of age after extremely preterm birth. N Engl J Med. 2005;352(1):9-19.

16. Hack M, Taylor HG, Drotar D. Chronic conditions, functional limitations, and special health care needs of school-aged children born with extremely low-birth-weight in the 1990s. JAMA 2005;294(3):318-25.

17. Hintz SR, Kendrick DE, Wilson-Costello DE, Das A, Bell EF, Vohr BR, et al. Early-Childhood Neurodevelopmental Outcomes Are Not Improving for Infants Born at $<25$ Weeks' Gestational Age. Pediatr. 2011;127(1):62-70. do1:10.1542/peds.2010-1150

18. Rysavy MA, Li L, Bell EF. Eunice Kennedy Shriver National Institute of Child Health and Human Development Neonatal Research Network. Between-hospital variation in treatment and outcomes in extremely preterm infants. N Engl J Med. 2015;372(19):1801-11.

19. Macfarlane PI. Non-viable delivery at 20-23 weeks gestation: observations and signs of life after birth. Arch Dis Child Fetal Neonatal Ed . 2003;88(3):199F-202. do1:10. 136/tn.88.3 flप

20. Partridge JC, Freeman H, Weiss E, Martinez AM. Delivery Room Resuscitation Decisions for Extremely Low Birthweight Infants in California. J Perinatol. 2001;21(1):27-33. do1:10.1038/s].jp.7200477.

21. Pignotti MS, Donzelli G. Perinatal care at the threshold of viability: an international comparison of practical guidelines for the treatment of extremely preterm births. Pediatr. 2008;121(1):e193-8.

22. Jensen EA, Lorch SA. Effects of a Birth Hospital's Neonatal Intensive Care Unit Level and Annual Volume of Very Low-BirthWeight Infant Deliveries on Morbidity and Mortality. JAMA Pediatr. 2015;169(8):e151906. do1:10.1001/ןamapediatrics.2015.1906.

23. Cifuentes J, Bronstein J, Phibbs CS, Phibbs RI, Schmitt SK, Carlo WA, et al. Mortality in low birth weight infants according to level of neonatal care at hospital of birth. Pediatr. 2002;09(5):745-51.

\section{Author biography}

Venugopalan, Professor and HOD

Manoj Narayanan K A, Associate Professor (D) https://orcid.org/00000002-7446-7733

Cite this article: Venugopalan, Narayanan K A M. Outcome of management of preterm babies born below 34 weeks of gestation in a level - 3 Neonatal ICU of a teaching institution in a backward district of Kerala- A retrospective analysis. IP Int J Med Paediatr Oncol 2021;7(1):11-15. 